Carnegie Mellon University

Research Showcase @ CMU

Heinz College Research

Heinz College

$7-2014$

\title{
An Empirical Analysis of the Impact of Pre-Release Movie Piracy on Box-Office Revenue
}

Liye Ma

University of Maryland

Alan Montgomery

Carnegie Mellon University, alm3@andrew.cmu.edu

Param Vir Singh

Carnegie Mellon University, psidhu@andrew.cmu.edu

Michael D. Smith

Carnegie Mellon University,mds@cmu.edu

Follow this and additional works at: http://repository.cmu.edu/heinzworks

Part of the Databases and Information Systems Commons, and the Public Policy Commons

This Working Paper is brought to you for free and open access by the Heinz College at Research Showcase @ CMU. It has been accepted for inclusion in Heinz College Research by an authorized administrator of Research Showcase @ CMU. For more information, please contact research-

showcase@andrew.cmu.edu. 


\title{
An Empirical Analysis of the Impact of Pre-Release Movie Piracy on Box-Office Revenue
}

\author{
Liye Ma, Alan L. Montgomery, Param Vir Singh, and Michael D. Smith \\ Carnegie Mellon University \\ Tepper School of Business and Heinz College \\ 5000 Forbes Ave \\ Pittsburgh, Pennsylvania
}

Forthcoming: Information Systems Research

Liye Ma (liyema@rhsmith.umd.edu) is an Assistant Professor at the Smith School of Business at the University of Maryland. Param Vir Singh (psidhu@andrew.cmu.edu) is an Associate Professor, and Alan L. Montgomery (alanmontgomery@cmu.edu) is an Associate Professor at the Tepper School of Business. Michael D. Smith is a Professor at the Heinz College and Tepper School of Business. The authors are affiliated with the iLab at the Heinz College. The authors thank participants at the 2009 Workshop on Information Systems and Economics and the 2009 Symposium on Statistical Challenges in Electronic Commerce Research for helpful comments on this research. This research was conducted as part of Carnegie Mellon University's Initiative for Digital Entertainment Analytics (IDEA), which receives unrestricted (gift) funding from the Motion Picture Association of American. We wish to note that there was no editorial control or oversight exerted over the research findings. The findings in the research are entirely our own. 


\title{
An Empirical Analysis of the Impact of Pre-Release Movie Piracy on Box-Office Revenue
}

\begin{abstract}
Digital distribution channels raise many new challenges for managers in the media industries. This is particularly true for movie studios where high-value content can be stolen and released through illegitimate digital channels, even prior to the release of the movie in legal channels. In response to this potential threat, movie studios have spent millions of dollars to protect their content from unauthorized distribution throughout the lifecycle of films. They have focused their efforts on the pre-release period under the assumption that pre-release piracy could be particularly harmful for a movie's success.

However, surprisingly, there has been little rigorous research to analyze whether, and how much, pre-release movie piracy diminishes legitimate sales. In this paper, we analyze this question using data collected from a unique Internet file-sharing site. We find that, on average, pre-release piracy causes a $19.1 \%$ decrease in revenue compared to piracy that occurs postrelease.

Our study contributes to the growing literature on piracy and digital media consumption by presenting evidence of the impact of Internet-based movie piracy on sales, and by analyzing pre-release piracy, a setting that is distinct from much of the extant literature.
\end{abstract}

Keywords: Movies, Box Office Revenue, Piracy, Forecasting 


\section{Introduction}

Digital distribution channels raise many new challenges for the creative industries. One notable challenge comes from digital piracy where firms must understand whether and how much digital piracy impacts revenue, how the threat from piracy may differ across the product's lifecycle, and how to develop strategies to respond to any threat posed by piracy. The challenge from piracy is particularly important for motion picture studios, where movies can cost hundreds of millions of dollars to produce and where these investments are "sunk" prior to the movie's release.

Understanding the impact of piracy early in a movie's lifecycle has become more salient for movie studios with pre-release piracy leaks occurring for a variety of prominent movie releases including "Star Wars Episode III: Revenge of the Sith", ${ }^{1}$ and Disney's "The Avengers" 2 and "Ratatouille". ${ }^{3}$ The most prominent recent piracy leak was the workprint copy of "X-Men Origins: Wolverine" which appeared on the Internet weeks before its official theatrical release, garnering huge attention (Stelter 2009), with some content sharing sites showing more than 200,000 downloads shortly after it appeared on their sites.

While studios spend millions of dollars in an attempt to prevent such pre-release piracy leaks, there is no rigorous empirical evidence regarding the impact of pre-release piracy. In the absence of solid empirical evidence, there are a number of opinions in the industry about the impact of pre-release piracy. On one hand, the Motion Picture Association of American championed passage of the Family Entertainment Copyright Act of 2005, which made pre-release distribution of movies a felony offense under U.S. law, punishable by up to 5 years in prison for a first-time offender, and up to 10 years in prison for repeat offenders. These severe punishments are consistent with the dominant view in the industry that pre-release piracy results in significant harm to the movie. For example, when a copy of "Wolverine" was leaked prior to its release, Fox issued a

\footnotetext{
1 http://news.bbc.co.uk/2/hi/entertainment/4563631.stm

2 http:/ / www.hollywoodreporter.com/thr-esq/avengers-pirated-box-office-marvel-disney-320936

${ }^{3}$ http://online.wsj.com/news/articles/SB119333891430471773
} 
statement saying that the theft of the movie "undermines the enormous efforts of the filmmakers and actors and, above all, hurts fans of the film."4

However, others in the industry have taken a much softer view of pre-release piracy. For example, when Hostel: Part II leaked, Lionsgate Entertainment's President Tom Ortenberg said 'It's distressing and disappointing, but it will have no meaningful impact on the box office." 5 Still others in the industry see piracy as potentially helping box office revenue: when a bootleg copy of the movie "Soul Plane" leaked prior to its release, one of its stars said "I don't think the bootleg is going to stop anything. I think people will want to see more of this because... a bootleg is like a buzz." 6

In the context of these important managerial and policy questions, our research is the first paper we are aware of that empirically analyzes the impact of pre-release piracy on theatrical revenue. As such, our paper informs an active managerial and policy question while also contributing to the growing information systems, marketing, and economics literatures on digital piracy. Several unique aspects of pre-release movie piracy make it important to study. First, pre-release piracy provides a cleaner view of the potential impact of piracy than what is likely available in other settings. Consider that most of the existing research on piracy looks at "simultaneous" piracy (i.e., a pirated version is available with the legitimate version), making it challenging to draw causal conclusions. In contrast, our research studies the effect of piracy in an arguably cleaner context: the pirated version is available before the first legitimate version is available, thus making it easier to draw causal inference. Secondly, pre-release piracy differs from other types of piracy in terms of the clientele it attracts. One major argument for the claim that piracy does not matter is that if the consumer is really interested in the content, then the consumer would buy the legitimate version-which usually has higher quality. Conversely, it is argued that those who are satisfied with the lower quality pirated version have low willingness-to-pay for the content, and would not have purchased the legitimate version anyway. However, this claim is harder to justify in the context of pre-release piracy. If the pirated version is made available before the legitimate one, it is not clear that people who download the pirated version are those with

\footnotetext{
${ }^{4}$ http://insidemovies.ew.com/2009/04/01/wolverine-leak/

${ }^{5}$ http://articles.latimes.com/2007/jun/01/business/fi-hostel1

${ }^{6}$ http://www.blackfilm.com/20040521/features/snoopdogg.shtml
} 
low willingness-to-pay. On the contrary, the very fact that these people would spend time downloading a low quality version online, knowing that if they just wait for a few days they could get the high quality version, suggests they are likely enthusiastic consumers. To the best of our knowledge, this clientele effect has not been discussed in literature.

Finally, we note that in addition to studying the impact of piracy prior to the legitimate release of the content, ours is also one of a small number of papers in the literature to study the impact of piracy in the theatrical window. From a revenue standpoint, the theatrical window continues to be an important source of revenue for studios. In 2002, when the BitTorrent protocol was first introduced, the theatrical window represented $\$ 9.2$ billion in revenue to studios, ${ }^{7}$ compared with $\$ 20.3$ billion in revenue in the home entertainment window (through DVD and VHS sales and rentals). ${ }^{8}$ In comparison, in 2012 theatrical revenue represented a slightly higher proportion of studio revenue, with the theatrical window representing $\$ 10.8$ billion in revenue, ${ }^{9}$ versus $\$ 18.0$ billion in the home entertainment window (through DVD and digital sales and rentals). ${ }^{10}$ It may also be important to study the impact of piracy in the theatrical window because, unlike most subsequent release windows for movies, there is typically no legitimate alternative channel available during the theatrical window: During the DVD window, consumers who want digital content can purchase using services such as iTunes, but owing to concerns from exhibitors, ${ }^{11}$ movie studios have generally avoided releasing in other channels during the theatrical window.

To study the effect of pre-release piracy in the theatrical window we adapt standard forecasting models from the marketing literature (Sawhney and Eliashberg 1996). We use data on major movie releases in the United States during a three-year period from 2006 to 2008. Our data include piracy information collected from a unique Internet file-sharing site, allowing us to analyze the impact of the existence of pre-release piracy on movie box office revenue. We find that pre-release piracy reduces predicted box office revenue by $19 \%$ on average relative to movies where piracy occurs after release, and that pre-release piracy has a larger

\footnotetext{
${ }^{7}$ http://www.the-numbers.com/market/2002/summary

${ }^{8} \mathrm{http}: / /$ www.dvdinformation.com/news/press/010903.htm

${ }^{9} \mathrm{http}: / /$ www.the-numbers.com/market/2012/summary

${ }^{10} \mathrm{http}: / /$ www.degonline.org/pressreleases/2013/DEG\%202012\%20Home\%20Entertaiment $\% 20$ Spending $\% 20$ Final $\% 20$ Ext.pdf

${ }^{11}$ See, for example, http://usatoday30.usatoday.com/life/movies/news/2011-05-25-video-on-demand_n.htm, and

http://www.deadline.com/2011/03/nato-responds-to-premium-vod-plan-between-directv-studios/
} 
impact in the early periods after release than in later periods, resulting in a slower rate of revenue decline over time for these movies. We believe these results provide useful guidance to both industry managers and to policymakers about the impact of pre-release piracy on sales, and also contribute to the growing academic literature on the impact of piracy.

\section{Literature Review}

The motion picture industry has attracted much attention from the information systems and marketing research communities over the last decade. ${ }^{12}$ Research has analyzed various factors that can contribute to a movie's success, including the movie's script (Eliashberg et al. 2007), advertising (Rennhoff and Wilbur 2008), the presence of star actors (Elberse 2007), critical reviews (Eliashberg and Shugan 1997), user reviews (Dellarocas et al. 2007, Duan et al. 2008), screen distributions (Swami et al. 1999), and seasonality and competition (Krider and Weinberg 1998), among others.

The impact of piracy on sales is a particularly important question for the motion picture industry, and one that has been debated both in industry and academia over the past decade. Two notable questions within this literature are first, does piracy impact legal consumption and second, how might the impact of piracy vary at different points within a media product's lifecycle?

With respect to the first question, while not uniform in their findings, the vast majority of papers in the literature find that piracy reduces sales in legal channels (see Danaher, Smith, and Telang (2014) for a recent review of this literature). While the majority of these papers have analyzed the impact of piracy on music sales, we are aware of 8 published papers that have analyzed the impact of piracy on motion picture sales. These papers are summarized in Table 1, which shows that 7 of these 8 published papers find that piracy results in significant harm to motion picture sales. We also note that Smith and Telang (2009), the one published paper that finds no evidence of harm, analyzes piracy during the broadcast television window which typically occurs 12-18 months after the theatrical release of the movie.

12 A thorough overview of the industry, open issues, and trends can be found in Eliashberg et al. (2006). 


\begin{tabular}{|c|c|c|}
\hline Citation & Primary Data & Result \\
\hline $\begin{array}{l}\text { Bounie et al. (2006, Rev. of } \\
\text { Econ. Res. on Copyright) }\end{array}$ & $\begin{array}{l}2005 \text { survey of movie piracy } \\
\text { and purchases from French } \\
\text { universities }\end{array}$ & $\begin{array}{l}\text { "[Piracy] has a strong [negative] impact on video [VHS } \\
\text { and DVD] purchases and rentals" but statistically no } \\
\text { impact on box office revenue. }\end{array}$ \\
\hline $\begin{array}{l}\text { Hennig-Thurau, Henning, } \\
\text { Sattler ( } 2007 \text {, Marketing } \\
\text { Science) }\end{array}$ & $\begin{array}{l}2006 \text { survey of German } \\
\text { movie purchase and piracy } \\
\text { intentions }\end{array}$ & $\begin{array}{l}\text { Piracy causes "substantial cannibalization of theater } \\
\text { visits, DVD rentals [and] purchases responsible for } \\
\text { annual revenue losses of } \$ 300 \text { million in Germany." }\end{array}$ \\
\hline $\begin{array}{l}\text { Rob and Waldfogel ( } 2007 \text {, } \\
\text { Journal of Industrial } \\
\text { Economics) }\end{array}$ & $\begin{array}{l}2005 \text { survey of U. Penn } \\
\text { students' movie purchase and } \\
\text { piracy behavior }\end{array}$ & $\begin{array}{l}\text { " }[\mathrm{U}] \text { npaid first [piracy] consumption reduces paid } \\
\text { consumption by about } 1 \text { unit." }\end{array}$ \\
\hline $\begin{array}{l}\text { DeVany and Walls ( } 2007, \\
\text { Review of Industrial } \\
\text { Organization) }\end{array}$ & $\begin{array}{l}\text { Box office revenue and the } \\
\text { supply of pirated content for } \\
\text { an unnamed movie }\end{array}$ & $\begin{array}{l}\text { "Piracy] of a major studio movie accelerated its box- } \\
\text { office decline and caused the picture to lose about } \$ 40 \\
\text { million in revenue." }\end{array}$ \\
\hline $\begin{array}{l}\text { Smith and Telang } \\
(2009, \text { MIS Quarterly) }\end{array}$ & $\begin{array}{l}\text { 2005-2006 Amazon DVD } \\
\text { sales ranks and BitTorrent } \\
\text { movie file downloads }\end{array}$ & $\begin{array}{l}\text { "[T] he availability of pirated content at [television } \\
\text { broadcast] has no effect on post-broadcast DVD sales } \\
\text { gains. }\end{array}$ \\
\hline $\begin{array}{l}\text { Danaher et al. ( } 2010 \text {, } \\
\text { Marketing Science) }\end{array}$ & $\begin{array}{l}\text { 2007-2008 BitTorrent } \\
\text { downloads of television } \\
\text { torrents }\end{array}$ & $\begin{array}{l}\text { The removal of NBC content from iTunes resulted in an } \\
11.4 \% \text { increase in demand for NBC piracy relative to } \\
\text { ABC, CBS, and FOX piracy. }\end{array}$ \\
\hline $\begin{array}{l}\text { Bai and Waldfogel ( } 2012 \text {, } \\
\text { Information Economics and } \\
\text { Policy) }\end{array}$ & $\begin{array}{l}2008-2009 \text { survey of Chinese } \\
\text { university students' movie } \\
\text { behavior }\end{array}$ & $\begin{array}{l}\text { "[T] hree quarters of [Chinese students'] movie } \\
\text { consumption is unpaid and ... each instance of [piracy] } \\
\text { displaces } 0.14 \text { paid consumption instances." }\end{array}$ \\
\hline $\begin{array}{l}\text { Danaher and Smith (2014, } \\
\text { International Journal of } \\
\text { Industrial Organization) }\end{array}$ & $\begin{array}{l}2011-2012 \text { digital movie sales } \\
\text { for } 12 \text { countries and } 3 \text { major } \\
\text { motion picture studios }\end{array}$ & $\begin{array}{l}\text { "[T] he shutdown of Megaupload and its associated sites } \\
\text { caused digital revenues for three major motion picture } \\
\text { studios to increase by } 6.5-8.5 \% "\end{array}$ \\
\hline
\end{tabular}

Table 1. Peer-Reviewed Journal Articles Analyzing the Impact of Piracy on Motion Picture Sales. Adapted from Danaher, Smith, and Telang (2014).

Each of these papers focuses on the impact of piracy after the release of the content in its initial channel. In contrast, ours is one of the first papers we are aware of in the literature to focus on the impact of piracy that occurs before the initial release of the product in any market. ${ }^{13}$ Focusing on the impact of "prerelease" piracy also helps answer the second question above: Where might piracy be most harmful to sales? Our results shed light on this question, and are consistent with the dominant view in the motion picture industry that pre-release piracy is particularly harmful to movie sales. Our results also complement results in the literature such as Smith and Telang (2009) who find no impact of piracy on movies shown on television, which occurs relatively late in a movie's lifecycle (typically 1-2 years after the movie was released in theaters).

\footnotetext{
${ }^{13}$ Hammond (Forthcoming) is the one other paper we are aware of that analyzes the impact of pre-release piracy, in his case prerelease music piracy.
} 
In addition to these published papers, we are aware of two currently unpublished manuscripts that analyze the impact of piracy on motion picture sales. The first, Danaher and Waldfogel (2012) analyze the impact of delaying the release of movies in international markets after their initial release in the domestic market, finding that delayed international release windows reduce box office revenue by an estimated $7 \%$. The second, Zentner (2010) uses country-level data on movie consumption and broadband penetration and concludes that peer-to-peer file sharing has a large and negative impact on retail purchases but no statistically significant impact on theatrical revenue or video rentals. In comparing Zentner's paper to our present results, we note that Zentner's results do not contradict our present results. Zentner is using increased broadband penetration as a proxy for file sharing, and then analyzing whether increased broadband penetration impacts movie sales. This is a very different setting than ours: a weak proxy for file sharing as opposed to direct observation of piracy, cross-country analysis as opposed to U.S. analysis, and a general impact (all types of file sharing) as opposed to a specific type of piracy (pre-release piracy).

In summary, our review of the literature suggests that our present results contribute to the literature by being the first paper we are aware of to analyze the impact of pre-release piracy on motion picture sales, but that our results showing that piracy harms motion picture sales are consistent with the findings in the vast majority of the literature.

We conclude this discussion with two specific hypotheses. The first is that the substitution effect of pre-release piracy will dominate any potential beneficial from piracy. Hence, we expect that pre-release piracy will decrease box-office revenue relative to piracy that occurs after release. Second, we hypothesize that consumers who are more eager to watch the movie are also more likely to search for a pre-release pirated version before the theatrical release. If a pirated version is available, these consumers are less likely to go to the theaters in the early weeks after the movie is released, since they have viewed the pre-release pirated copy. Therefore, our second hypothesis is that we expect the reduction in box office revenue from pre-release piracy to be more significant in the early weeks of the theatrical release than in the later weeks. 


\section{Data}

We collect our data from four sources: BoxOfficeMojo, IMDB, Nielsen Research, and Vcdquality.com. ${ }^{14}$ Our data consist of all movies whose wide release occurred between February 2006 and December 2008. We collect various characteristics of these movies from both IMDB and BoxOfficeMojo, including distributor, genre, MPAA rating, director appeal, star appeal, user rating, and critic rating. Additionally, we obtained box office revenue information from Nielsen Research. Table 2 lists all the variables collected from these sources for our study, the description of the variable, and information source.

Our information about pre-release movie piracy comes from vcdquality.com. This is not an Internet file-sharing site, but instead is a site that monitors popular Internet file sharing sites. It posts messages on its website once a pirated copy of a movie becomes available at other piracy sites. Each message includes the date of availability, which allows us to infer the presence of piracy that occurred prior to the general release date for the movie. Specifically, we know the date on which a pirated copy is posted from vcdquality.com and we compare this to the official theatrical release date of the corresponding movie listed by BoxOfficeMojo. The difference between these two dates allows us to detect whether pre-release piracy is present for a particular movie. ${ }^{15}$ Vcdquality.com also tracks user ratings of the video and audio quality of the pirated content, allowing us to collect a measure of the video and audio quality of the pirate release.

There are two variables in our data that have missing values. First, there are 117 movies for which production budget information is missing. To handle this issue, we set the production budget of all these movies to the mean of the known production budgets, and create an indicator variable to whether the production budget for a movie missing. The coefficient of the indicator variable captures any systematic difference between the group of movies with known budgets and the group with unknown budgets, should such a difference exist. (In section 5.3 we also check the robustness of our findings by removing these

\footnotetext{
14 All information is available on the Internet, either for free or via a subscription.

15 As noted above, in this paper we define pre-release piracy as piracy that occurs prior to the widespread theatrical release of the movie. This sort of piracy can result from a variety of sources, but notably from leaks in the production process (e.g., leaked workprints as in the case of "Hostel II" and "X-Men Wolverine" or through leaks from pre-release viewings of the movies through | previews, screeners, or film festivals).
} 
missing observations.) Secondly, there are 109 movies with missing piracy quality, for which we also set the missing value to the mean of the movies with known piracy quality.

\begin{tabular}{|c|c|c|}
\hline Variable & Description & Source \\
\hline Box Office & The US box office revenue of a movie in a week. & Nielsen Research \\
\hline Budget & $\begin{array}{l}\text { The estimated production budget of the movie. } \\
\text { (This information is not available for all movies.) }\end{array}$ & $\begin{array}{l}\text { IMDB.com, } \\
\text { BoxOfficeMojo.com }\end{array}$ \\
\hline Opening Screens & $\begin{array}{l}\text { The number of screens on which the movie was } \\
\text { shown in the opening weekend. }\end{array}$ & BoxOfficeMojo.com \\
\hline Director Appeal & $\begin{array}{l}\text { A binary indicator of the presence of a star director } \\
\text { in the movie. The indicator is set to one if the past } \\
\text { average box office revenue of the director is higher } \\
\text { than } \$ 50 \text { million. }\end{array}$ & $\begin{array}{l}\text { BoxOfficeMojo.com } \\
\text { Inferred }\end{array}$ \\
\hline User Rating & $\begin{array}{l}\text { The average movie rating posted by viewers. The } \\
\text { rating is given on a scale of } 1 \text { (worst) to } 10 \text { (best). }\end{array}$ & IMDB.com \\
\hline Critic Rating & $\begin{array}{l}\text { The metascore of the movie, based on critic } \\
\text { reviews. The rating is given on a scale of } 1 \text { (worst) } \\
\text { to } 100 \text { (best). }\end{array}$ & IMDB.com \\
\hline Star Appeal & $\begin{array}{l}\text { A binary indicator of the presence of stars in the } \\
\text { cast of the movie. A movie is considered to have a } \\
\text { star if any of the top four actors/actresses have } \\
\text { either been nominated for or won an academy } \\
\text { award before the playing in the movie. }\end{array}$ & $\begin{array}{l}\text { IMDB.com } \\
\text { Inferred }\end{array}$ \\
\hline Distributor & The distributor of the movie. & BoxOfficeMojo.com \\
\hline Rating & The MPAA rating of the movie. & BoxOfficeMojo.com \\
\hline Genre & The genre of the movie. & BoxOfficeMojo.com \\
\hline Pirated Quality & $\begin{array}{l}\text { The average of video and audio quality rating of } \\
\text { the pirated copy according to vcdquality.com. (Not } \\
\text { all copies received a rating.) }\end{array}$ & Vcdquality.com \\
\hline $\begin{array}{l}\text { Pre-Release Piracy } \\
\text { Indicator }\end{array}$ & $\begin{array}{l}\text { An indicator variable for the existence of pre- } \\
\text { release piracy. This is inferred when the piracy date } \\
\text { occurs before the wide release date. }\end{array}$ & $\begin{array}{l}\text { Inferred from } \\
\text { Vcdquality.com and } \\
\text { BoxOfficeMojo.com }\end{array}$ \\
\hline $\begin{array}{l}\text { Pre-Release Piracy } \\
\text { Week }\end{array}$ & $\begin{array}{l}\text { The number of weeks before the wide release date } \\
\text { that a pre-release pirated version became available } \\
\text { (only movies with pre-release piracy are used to } \\
\text { compute this value) }\end{array}$ & $\begin{array}{l}\text { Inferred from } \\
\text { Vcdquality.com and } \\
\text { BoxOfficeMojo.com }\end{array}$ \\
\hline
\end{tabular}

Table 2. Description of Variables

The descriptive statistics of all our variables are reported in Table 3. For distributor, MPAA rating, and genre, indicator variables were created representing each value. The data set consists of 533 movies, which is the entire set of all movies identified by BoxOfficeMojo as having wide release during our time period. The average production budget of a movie is $\$ 47.15$ million, the average number of opening screens is 2,349 , and the average box office revenue of a movie is $\$ 52.61$ million. Production budgets are as low as 
$\$ 500$ thousand and as high as $\$ 300$ million, while box office revenue ranges from $\$ 130$ thousand to $\$ 533$ million. This shows the broad coverage of the movie spectrum of our dataset, and illustrates the large disparity in terms of quality and popularity of the movies.

\begin{tabular}{|c|c|c|c|c|c|}
\hline \multicolumn{2}{|l|}{ Variable } & Mean & $\begin{array}{r}\text { Standard } \\
\text { Deviation }\end{array}$ & Minimum & Maximum \\
\hline \multicolumn{2}{|c|}{ Box Office (\$ million) } & 52.61 & 63.78 & 0.13 & 533.35 \\
\hline \multicolumn{2}{|c|}{ Budget ( $\$$ million) } & 47.15 & 40.70 & 0.5 & 300 \\
\hline \multicolumn{2}{|c|}{ Opening Screens } & 2349 & 967 & 2 & 4366 \\
\hline \multicolumn{2}{|c|}{ Director Appeal } & 0.21 & 0.41 & 0 & 1 \\
\hline \multicolumn{2}{|c|}{ Star Appeal } & 0.47 & 0.50 & 0 & 1 \\
\hline \multicolumn{2}{|l|}{ User Rating } & 6.10 & 1.32 & 1 & 8.9 \\
\hline \multicolumn{2}{|l|}{ Critic Rating } & 39.68 & 17.55 & 1 & 84 \\
\hline \multirow[t]{8}{*}{ Distributor } & Warner & 0.11 & 0.32 & 0 & 1 \\
\hline & Universal & 0.10 & 0.29 & 0 & 1 \\
\hline & Paramount & 0.11 & 0.31 & 0 & 1 \\
\hline & Fox & 0.14 & 0.34 & 0 & 1 \\
\hline & Sony & 0.14 & 0.35 & 0 & 1 \\
\hline & Newline & 0.06 & 0.23 & 0 & 1 \\
\hline & Lionsgate & 0.08 & 0.26 & 0 & 1 \\
\hline & MGM & 0.06 & 0.23 & 0 & 1 \\
\hline \multirow[t]{3}{*}{ Rating } & G & 0.04 & 0.20 & 0 & 1 \\
\hline & $\mathrm{R}$ & 0.36 & 0.48 & 0 & 1 \\
\hline & PG13 & 0.42 & 0.49 & 0 & 1 \\
\hline \multirow[t]{7}{*}{ Genre } & Action & 0.12 & 0.32 & 0 & 1 \\
\hline & Comedy & 0.31 & 0.46 & 0 & 1 \\
\hline & Drama & 0.23 & 0.42 & 0 & 1 \\
\hline & Adventure & 0.06 & 0.23 & 0 & 1 \\
\hline & Horror & 0.12 & 0.33 & 0 & 1 \\
\hline & Thriller & 0.13 & 0.34 & 0 & 1 \\
\hline & Animation & 0.17 & 0.25 & 0 & 1 \\
\hline \multicolumn{2}{|c|}{ Pirated Quality } & 6.22 & 1.58 & 1 & 9.5 \\
\hline \multicolumn{2}{|c|}{ Pre-Release Piracy Indicator } & 0.10 & 0.30 & 0 & 1 \\
\hline \multicolumn{2}{|c|}{ Pre-Release Piracy Week } & 7.04 & 11.07 & 1 & 65 \\
\hline \multicolumn{2}{|c|}{ Number of Movies } & \multicolumn{4}{|c|}{533} \\
\hline
\end{tabular}

Table 3. Descriptive Statistics for our entire dataset. 


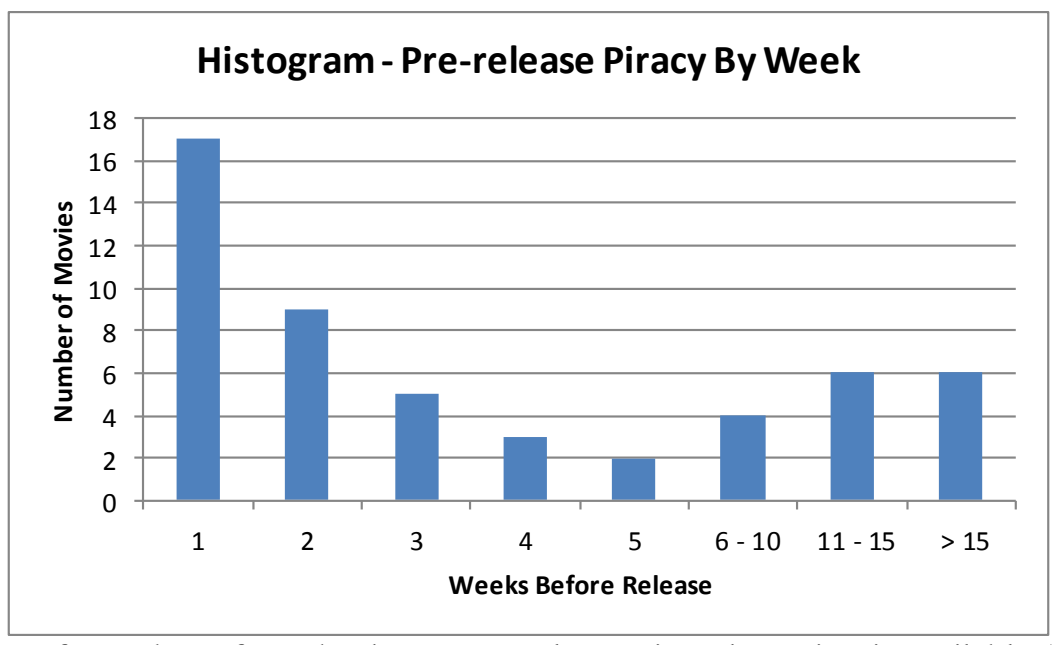

Figure 1. Histogram of Number of Weeks that a Pre-Release Pirated Version is available (for the 52 movies in our dataset with pre-release piracy).

\subsection{Pre-release Piracy}

Of the 533 movies in the dataset, 52 had pre-release piracy: a pirated version became available before the official release of the movie in theaters. This suggests that while pre-release piracy occurs for only about $10 \%$ of all movies, it is still significant enough level to warrant detailed empirical investigation. For movies that have pre-release piracy, the pirated version becomes available on average 7 weeks before the theatrical release. Figure 1 shows the number of weeks before release when the pre-release piracy occurs. While half of the pre-release piracy incidents occurred within two weeks prior to the official release, six movies had prerelease pirated versions available more than fifteen weeks before the theatrical release date. Thus in addition to analyzing the average impact of pre-release piracy, it may be valuable to analyze whether the impact depends on how early piracy happened. 


\begin{tabular}{|c|c|c|c|c|c|}
\hline \multirow{2}{*}{ Variable } & & \multicolumn{2}{|c|}{ With Pre-release Piracy } & \multicolumn{2}{|c|}{$\begin{array}{c}\text { Without Pre-release } \\
\text { Piracy }\end{array}$} \\
\hline & & Mean & $\begin{array}{l}\text { Standard } \\
\text { Deviation }\end{array}$ & Mean & $\begin{array}{l}\text { Standard } \\
\text { Deviation }\end{array}$ \\
\hline \multicolumn{2}{|c|}{ Box Office ( $\$$ million) } & 52.65 & 62.58 & 52.61 & 63.98 \\
\hline \multicolumn{2}{|c|}{ Budget (\$ million) } & 46.31 & 40.74 & 47.23 & 40.74 \\
\hline \multicolumn{2}{|c|}{ Opening Screens } & 1799 & 1071 & 2409 & 938 \\
\hline \multicolumn{2}{|c|}{ Director Appeal } & 0.25 & 0.44 & 0.21 & 0.40 \\
\hline \multicolumn{2}{|c|}{ Star Appeal } & 0.52 & 0.50 & 0.47 & 0.50 \\
\hline \multicolumn{2}{|l|}{ User Rating } & 7.00 & 1.06 & 6.00 & 1.31 \\
\hline \multicolumn{2}{|l|}{ Critic Rating } & 48.83 & 20.29 & 38.69 & 16.95 \\
\hline \multirow[t]{8}{*}{ Distributor } & Warner & 0.10 & 0.30 & 0.11 & 0.32 \\
\hline & Universal & 0.12 & 0.32 & 0.09 & 0.29 \\
\hline & Paramount & 0.12 & 0.32 & 0.10 & 0.31 \\
\hline & Fox & 0.10 & 0.30 & 0.14 & 0.35 \\
\hline & Sony & 0.10 & 0.30 & 0.15 & 0.36 \\
\hline & Newline & 0.02 & 0.14 & 0.06 & 0.24 \\
\hline & Lionsgate & 0.06 & 0.24 & 0.08 & 0.27 \\
\hline & MGM & 0.08 & 0.27 & 0.06 & 0.23 \\
\hline \multirow[t]{3}{*}{ Rating } & G & 0.04 & 0.19 & 0.04 & 0.2 \\
\hline & $\mathrm{R}$ & 0.50 & 0.50 & 0.34 & 0.48 \\
\hline & PG13 & 0.35 & 0.48 & 0.43 & 0.5 \\
\hline \multirow[t]{7}{*}{ Genre } & Action & 0.12 & 0.32 & 0.12 & 0.32 \\
\hline & Comedy & 0.17 & 0.38 & 0.32 & 0.47 \\
\hline & Drama & 0.40 & 0.50 & 0.21 & 0.40 \\
\hline & Adventure & 0.08 & 0.27 & 0.05 & 0.23 \\
\hline & Horror & 0.12 & 0.32 & 0.12 & 0.33 \\
\hline & Thriller & 0.10 & 0.30 & 0.14 & 0.34 \\
\hline & Animation & 0.04 & 0.19 & 0.07 & 0.26 \\
\hline \multicolumn{2}{|c|}{ Pirated Quality } & 7.13 & 1.53 & 6.12 & 1.55 \\
\hline \multicolumn{2}{|c|}{ Pre-Release Piracy Indicator } & 1.00 & 0.00 & 0.00 & 0.00 \\
\hline \multicolumn{2}{|c|}{ Pre-Release Piracy Week } & 7.04 & 11.07 & NA & \\
\hline \multicolumn{2}{|c|}{ Number of Movies } & \multicolumn{2}{|c|}{52} & \multicolumn{2}{|c|}{481} \\
\hline
\end{tabular}

Table 4. Descriptive Statistics for Movies with and without Pre-release Piracy

In Table 4, we compare descriptive statistics for all movies with pre-release piracy versus those where piracy occurs after widespread release. ${ }^{16}$ This table shows that movies with pre-release piracy are fairly similar to those without. Box office revenue is almost identical between movies with ( $\$ 52.65$ million) and without

\footnotetext{
${ }^{16}$ We note that essentially every movie experiences piracy at some point in its lifecycle and thus our distinction is only between movies that experience piracy prior to their release and movies that experience piracy after release.
} 
(\$52.61 million) pre-release piracy, as is production cost $(\$ 46.31$ million for pre-release piracy movies versus $\$ 47.23$ million for other movies). While movies with pre-release piracy open on fewer screens than other movies do $(1,700$ versus 2,409$)$ the difference is not statistically significant. However, there are some differences between the two groups. First, movies with pre-release piracy have higher user ratings (7.13 vs. 6.12) and critic ratings (48.83 vs. 38.69$)$. Second, movies with pre-release piracy are more likely to be "R" rated than those without $(0.50$ vs. 0.34$)$. Finally, drama movies are more likely to experience pre-release piracy ( 0.40 vs. 0.21$)$ and comedies less likely to experience pre-release piracy $(0.17$ vs. 0.32$)$ than are other movies in our sample. Although box office revenues are, on average, similar between movies with pre-release piracy and those without, because of the differences in movie characteristics between the two groups we cannot conclude anything about the impact of piracy just from summary statistics. On one hand movies with prerelease piracy generally have higher user and critic ratings, which ceteris paribus would generally indicate higher revenue. Conversely, movies with pre-release piracy generally have fewer opening screens, which would indicate less revenue. To understand the effect of pre-release piracy, therefore, detailed quantitative modeling is needed which controls for relevant movie characteristics. Developing such a model is the subject of the next section.

\section{An Exponential Model of Movie Box Office Revenue}

The preceding discussion suggests that it is important to account for a large set of movie characteristics to reliably identify the effect of pre-release piracy. In this section, we develop a regression model to better understand the nature of the relationship between pre-release piracy and movie box office revenue. Most movies see their highest level of sales in the opening week of wide-release, with sales declining exponentially over time. Consistent with the extant literature (e.g. Sawhney and Eliashberg 1996, Krider and Weinberg 1998), we model movie box office revenue using an exponentially declining model:

$$
y_{i t}=m_{i} e^{-\eta_{i} t+\varepsilon_{i t}}=e^{\ln \left(m_{i}\right)-\eta_{i} t+\varepsilon_{i t}}
$$


where $y_{i t}$ is the box office revenue of movie $i$ at time $t$, and, $m_{i}$ and $\eta_{i}$ represent the market potential ${ }^{17}$ and the rate of decline of movie sales, respectively.

Market potential and rate of decline likely depend on movie characteristics and pre-release piracy, and we model these variables in the context of a hierarchical (or equivalently a random effects) model as follows:

$$
\begin{gathered}
\ln \left(m_{i}\right)=\mathbf{X}_{\mathbf{i}}^{\prime} \boldsymbol{\beta}_{\mathbf{i}}+\rho \operatorname{Pir}_{i}+\zeta_{i} \\
\eta_{i}=\mathbf{Z}_{\mathbf{i}}^{\prime} \boldsymbol{\gamma}_{\mathbf{i}}+\tau \operatorname{Pir}_{i}+\xi_{i}
\end{gathered}
$$

where $\mathbf{X}_{\mathbf{i}}$ is a $k \times 1$ vector of the characteristics of movie $i$ which are related to market potential, $\mathbf{Z}_{\mathbf{i}}$ is an $l \times 1$ vector of the characteristics of movie $i$ that influence the rate of decay, and $P i r_{i}$ is an indicator for the existence of pre-release piracy for the movie (e.g., the pre-release piracy indicator in Table 2).

Taking the logarithm of (1) and substituting in (2) and (3) yields a log-linear model:

$$
\ln \left(y_{i t}\right)=\mathbf{X}_{\mathbf{i}}^{\prime} \boldsymbol{\beta}_{\mathbf{i}}-\mathbf{Z}_{\mathbf{i}}^{\prime} \boldsymbol{\gamma}_{\mathbf{i}} t+\rho \operatorname{Pir}_{i}-\tau P \operatorname{Pi}{ }_{i} t+\varepsilon_{i t}^{*} \text {, where } \varepsilon_{i t}^{*}=\varepsilon_{i t}+\zeta_{i}+t \xi_{i}
$$

The hierarchical nature of the model induces heteroskedasticity across movies, but otherwise can be estimated through standard econometric methods. Our main hypothesis is that pre-release piracy lowers market potential (i.e., we expect $\rho<0) .{ }^{18}$ We also hypothesize that the reduction in revenue will be larger in early periods than in later periods, resulting in a slower rate of decline over time for movies with pre-release piracy (i.e., $\tau<0$ ). Additionally, because nearly all movies in our data experience piracy after release, we cannot use our model to separately estimate the impact of post-release piracy (versus a hypothetical world

\footnotetext{
${ }^{17}$ If the first period is indexed by 0 , then the total box-office revenue if the movie is played perpetually is $\sum_{t=0}^{\infty} m_{i} e^{-\eta_{i} t}=\frac{m_{i}}{1-e^{-\eta_{i}}}$, which is proportional to $m_{i}$ when the rate of decay, $\eta_{i}$, is held constant. In another words, $m_{i}$ represents the size of the market while $\eta_{i}$ represents the distribution of the sales over time. Hence we term $m_{i}$ the market potential in the context of the model, which follows terminology used in the marketing literature (Lehmann and Weinberg 2000, Lee, Boatwright and Kamakura 2003, Dellarocas et al 2007). Although market potential can also be described as market attractiveness (Ainslie, Dreze and Zufryden 2005), box office attraction (Sawhney and Eliashberg 1996), or simply "potential" (Eliashberg et al 2000).

${ }^{18}$ Furthermore, to be consistent with the hypothesis, the reduction in the market potential parameter should outweigh any positive effect of a reduced rate of decay, so that the net effect on overall revenue is reduced.
} 
where piracy does not exist). Thus, one should interpret our estimates in terms of the additional impact of pre-release piracy over and above any impact that would exist from piracy that occurs after release.

\begin{tabular}{|c|c|c|c|c|c|}
\hline & & \multicolumn{2}{|c|}{ With Pre-release Piracy } & \multicolumn{2}{|c|}{$\begin{array}{c}\text { Without Pre-release } \\
\text { Piracy }\end{array}$} \\
\hline \multicolumn{2}{|l|}{ Variable } & Mean & $\begin{array}{l}\text { Standard } \\
\text { Deviation }\end{array}$ & Mean & $\begin{array}{l}\text { Standard } \\
\text { Deviation }\end{array}$ \\
\hline \multicolumn{2}{|c|}{ Box Office ( $\$$ million) } & 55.78 & 64.03 & 58.17 & 65.79 \\
\hline \multicolumn{2}{|c|}{ Budget (\$ million) } & 48.63 & 41.67 & 49.76 & 42.33 \\
\hline \multicolumn{2}{|c|}{ Opening Screens } & 1795 & 1077 & 2509 & 920 \\
\hline \multicolumn{2}{|c|}{ Director Appeal } & 0.25 & 0.44 & 0.22 & 0.42 \\
\hline \multicolumn{2}{|c|}{ Star Appeal } & 0.56 & 0.50 & 0.47 & 0.50 \\
\hline \multicolumn{2}{|l|}{ User Rating } & 7.18 & 0.88 & 6.08 & 1.27 \\
\hline \multicolumn{2}{|l|}{ Critic Rating } & 50.98 & 19.50 & 39.44 & 16.47 \\
\hline \multirow[t]{8}{*}{ Distributor } & Warner & 0.10 & 0.31 & 0.13 & 0.34 \\
\hline & Universal & 0.13 & 0.33 & 0.09 & 0.29 \\
\hline & Paramount & 0.13 & 0.33 & 0.11 & 0.32 \\
\hline & Fox & 0.10 & 0.31 & 0.16 & 0.36 \\
\hline & Sony & 0.08 & 0.28 & 0.14 & 0.35 \\
\hline & Newline & 0.02 & 0.14 & 0.06 & 0.24 \\
\hline & Lionsgate & 0.04 & 0.20 & 0.06 & 0.24 \\
\hline & MGM & 0.08 & 0.28 & 0.06 & 0.24 \\
\hline \multirow[t]{3}{*}{ Rating } & G & 0.04 & 0.20 & 0.05 & 0.21 \\
\hline & $\mathrm{R}$ & 0.50 & 0.50 & 0.32 & 0.47 \\
\hline & PG13 & 0.33 & 0.48 & 0.45 & 0.5 \\
\hline \multirow[t]{7}{*}{ Genre } & Action & 0.13 & 0.33 & 0.11 & 0.32 \\
\hline & Comedy & 0.19 & 0.39 & 0.34 & 0.47 \\
\hline & Drama & 0.44 & 0.50 & 0.19 & 0.39 \\
\hline & Adventure & 0.08 & 0.28 & 0.06 & 0.24 \\
\hline & Horror & 0.04 & 0.20 & 0.12 & 0.33 \\
\hline & Thriller & 0.08 & 0.28 & 0.13 & 0.33 \\
\hline & Animation & 0.04 & 0.20 & 0.07 & 0.26 \\
\hline \multicolumn{2}{|c|}{ Pirated Quality } & 7.09 & 1.57 & 6.13 & 1.57 \\
\hline \multicolumn{2}{|c|}{ Pre-Release Piracy Indicator } & 1.00 & 0.00 & 0.00 & 0.00 \\
\hline \multicolumn{2}{|c|}{ Pre-Release Piracy Week } & 7.46 & 11.43 & NA & \\
\hline \multicolumn{2}{|c|}{ Number of Observations } & \multicolumn{2}{|c|}{48} & \multicolumn{2}{|c|}{427} \\
\hline
\end{tabular}

Table 5. Descriptive Statistics for Movies with and without Pre-release Piracy used for model estimation

Our dataset contains a total of 533 movies, but we have a number of movies that were shown for a brief period of time. Therefore to ensure that we have adequate information to fit a movie's revenue curve, 
we kept only the movies that were exhibited in theaters for at least six weeks. This removed 58 movies, leaving 475 remaining in the dataset (including 48 movies that had pre-release piracy). The descriptive statistics of the most important variables for the movies used in this analysis are given in Table 5. The statistics are very close to those of the overall dataset provided in Tables 3 and 4.

\subsection{Empirical Results with Homogenous Rate of Decline}

We first analyze a parsimonious model setup in which we assume a homogeneous rate of decline across movies. The prior literature has shown that most movie characteristics included in our dataset impact market potential (Sawhney and Eliashberg 1996, Dellarocas et al. 2007). Therefore, we include all movie characteristics that are available to us in vector $\mathbf{X}_{\mathbf{i}}$ (as listed in Table 2). This includes movie distributor, genre, MPAA rating, director appeal, star appeal, budget, screen, user rating, and critic rating. In this first analysis, we assume a homogeneous rate of decline, i.e. all movies have the same rate of revenue decline over time, unless altered by pre-release piracy $\left(\eta_{i}=\lambda+\tau P i r_{i}\right)$. Equation (4) thus becomes:

$$
\ln \left(y_{i t}\right)=\mathbf{X}_{\mathbf{i}}^{\prime} \boldsymbol{\beta}_{\mathbf{i}}-\lambda t+\rho \operatorname{Pir}_{i}-\tau P i r_{i} t+\varepsilon_{i t}^{*}
$$

Equation (5) includes movie-specific random effects to account for potential unobserved effects at the movie level. Such effects may induce correlated residuals, rendering the standard error estimate invalid if Pooled OLS is used. Therefore, we estimate the model using Feasible GLS. The result of the estimation is reported in Table 6.

The results on the control variables in Table 6 are generally in line with expectations. These results show that the production budget and the number of screens both positively influence movie revenue (i.e., the market potential parameter). The coefficient on the missing budget indicator variable is negative and statistically significant, suggesting that, movies with missing budgets on IMDB are typically smaller than those with known budget information. Also, as expected, movies with star directors have higher expected revenue, as do movies with higher user and critic ratings. Most major studios produce movies with higher expected revenue (compared with the baseline which is non-brand-name studios), though not all are statistically 
significant and there are exceptions (e.g., Newline and MGM). Movies rated R have lower expected revenue, potentially due to the restriction on the number of potential viewers, whereas movies rated $G$ have higher expected revenue than other movies do. Finally, comedy and horror movies have higher expected revenue than other movies. These results are in line with our expectations and with the prior literature.

\begin{tabular}{l|cll|c}
\hline \hline Parameter & Estimate & & Parameter & Estimate \\
\cline { 1 - 2 } \cline { 1 - 2 } Constant & $7.4631(1.2412)^{* * *}$ & & Warner & $0.2319(0.1618)$ \\
$\tau$ & $-0.1929(0.0222)^{* * *}$ & & Universal & $0.4701(0.1839)^{*}$ \\
$\rho$ & $-0.7399(0.1767)^{* * *}$ & & Paramount & $0.2955(0.1764)$ \\
$\lambda$ & $0.7600(0.0071)^{* * *}$ & Fox & $0.1793(0.1561)$ \\
Budget & $0.3878(0.0759)^{* * *}$ & Sony & $0.4489(0.1631)^{* *}$ \\
MissingBudget & $-0.9032(0.1253)^{* * *}$ & & Newline & $-0.0329(0.2166)$ \\
Screen & $0.4233(0.0783)^{* * *}$ & Lionsgate & $0.5159(0.2186)^{*}$ \\
Director Appeal & $0.2358(0.1196)^{*}$ & & MGM & $-0.5277(0.2115)^{*}$ \\
User Rating & $0.1703(0.0599)^{* *}$ & & Action & $0.0044(0.1587)$ \\
Critic Rating & $0.0198(0.0041)^{* * *}$ & Comedy & $0.4414(0.1431)^{* *}$ \\
Star Appeal & $0.0953(0.1011)$ & & Drama & $-0.1411(0.1479)$ \\
G & $0.6104(0.2643)^{*}$ & & Adventure & $0.3821(0.2186)$. \\
R & $-0.7920(0.1618)^{* * *}$ & Horror & $0.4361(0.1799)^{*}$ \\
PG13 & $-0.1962(0.1403)$ & & Thriller & $0.1055(0.1630)$ \\
& & Animation & $0.0337(0.2328)$ \\
\hline \hline
\end{tabular}

AIC: 6711, BIC: 6902

Standard errors are given in parenthesis. The significance of the estimates are denoted by the following codes: $<0.001$ : $^{(* * *)},<0.01$ : $^{(* *)},<0.05$ : $^{\text {(*) }}<0.1$ : '?

Table 6. Estimation Results for Homogeneous Rate of Decline

With respect to our variable of interest, the results in Table 6 show the coefficient of piracy on market potential is -0.7399 (statistically significant at 0.01 level). This suggests that pre-release piracy reduces the expected revenue of movies. The results also show that the coefficient of piracy on rate of revenue decline over time is -0.1929 (statistically significant at .001). This confirms the hypothesis that pre-release piracy has a stronger impact on revenue early in the movie's lifecycle.

Since the rate of decline without pre-release piracy is 0.76 , these parameter estimates imply a $28.9 \%$ revenue loss arising from pre-release piracy, assuming the movie is played for 12 weeks (which is the average 
theatrical run in our dataset). ${ }^{19}$ This is a substantial reduction in revenue, suggesting that pre-release piracy significantly harms movie sales. Although the impact of piracy is not apparent at the summary statistic level, the impact becomes clear once other movie characteristics are accounted for in the model (e.g. movies with pre-release piracy have higher user and critic ratings, and the corresponding positive coefficients in Table 6 show that such movies should have had higher revenues ceteris paribus). Movies with pre-release piracy appear to have lower expected revenue than would be expected of similar movies without pre-release piracy. Note that this revenue loss is relative to the baseline case of a movie that experiences piracy only after release, it does not reflect what revenue would be in the absence of piracy altogether.

\subsection{Empirical Results for Heterogeneous Rate of Decline}

The assumption of a homogeneous rate of revenue decline in the previous analysis, while parsimonious, is strong. Not all movies are the same, and some movies see their sales decline faster than others do. To control for the factors that may influence this rate of decline, in this section we introduce heterogeneity into the rate of decline across movies (the $\mathbf{Z}^{\prime}{ }_{\mathbf{i}} \boldsymbol{\gamma}_{\mathbf{i}} \boldsymbol{t}$ term in Equation (4)). In determining $\mathbf{Z}_{\mathbf{i}}$, a matrix of movie characteristics that may influence decline, we note that the rate of decline in revenue should be primarily driven by quality-related characteristics, e.g., higher quality movies may receive more positive word-of-mouth after release and would have a slower rate of revenue decline than lower quality movies do. Among the movie characteristics that we gathered, we include director appeal, star appeal, user ratings, and critic ratings in $\mathbf{Z}_{\mathbf{i}}$. We again estimate the model using Feasible GLS.

The result of this estimation is reported in Table 7. Consistent with our hypotheses, the coefficient of pre-release piracy on market potential is negative (-0.40), and statistically significant at the .05 level. The coefficient of piracy on the rate of sales decay is also negative, (-0.10), and statistically significant at the .01 level. With the rate of decline in revenue prior to accounting for piracy varying from movie to movie, the total reduction in box office revenue arising from pre-release piracy also depends on other movie

${ }^{19}$ The total box office revenue of the first $w$ weeks is calculated as $\sum_{t=1}^{w} m_{i} e^{-\eta_{i} t}$. Then revenues with and without pre-release piracy based on the parameter estimates are computed (the two scenarios have different $m_{i}$ and $\eta_{i}$ ), and the difference between them is the revenue loss due to pre-release piracy. 
characteristics. Based on the average movie characteristics in the dataset, the average rate of decline in revenue before accounting for piracy is 0.75 (very close to the estimate in the previous section). These coefficient estimates imply a $19.1 \%$ total reduction in box office revenue arising from pre-release piracy, assuming as before that the movie is played for 12 weeks.

\begin{tabular}{|c|c|c|c|}
\hline Parameter & Estimate & Parameter & Estimate \\
\hline Constant & $7.4290(1.2419)^{* * *}$ & Warner & $0.2319(0.1619)$ \\
\hline$\tau$ & $-0.0965(0.0208)^{* * *}$ & Universal & $0.4701(0.1840)^{*}$ \\
\hline$\rho$ & $-0.4024(0.1746)^{*}$ & Paramount & $0.2955(0.1765)$ \\
\hline$\lambda$ & $0.7503(0.0064)^{* * *}$ & Fox & $0.1793(0.1562)$ \\
\hline Budget & $0.3878(0.0760)^{* * *}$ & Sony & $0.4489(0.1632)^{* *}$ \\
\hline MissingBudget & $-0.9032(0.1253)^{* * *}$ & Newline & $-0.0329(0.2168)$ \\
\hline Screen & $0.4233(0.0784)^{* * *}$ & Lionsgate & $0.5159(0.2187)^{*}$ \\
\hline Director Appeal & $0.0256(0.1302)$ & MGM & $-0.5278(0.2117)^{*}$ \\
\hline User Rating & $0.1418(0.0650)^{*}$ & Action & $0.0044(0.1588)$ \\
\hline Critic Rating & $-0.0044(0.0045)$ & Comedy & $0.4414(0.1432)^{* *}$ \\
\hline Star Appeal & $-0.1451(0.1104)$ & Drama & $-0.1411(0.1480)$ \\
\hline G & $0.6104(0.2645)^{*}$ & Adventure & 0.3821 (0.2187) \\
\hline $\mathrm{R}$ & $-0.7920(0.1619)^{* * *}$ & Horror & $0.4361(0.1800)^{*}$ \\
\hline \multirow[t]{2}{*}{ PG13 } & $-0.1962(0.1404)$ & Thriller & 0.1055 (0.1631) \\
\hline & & Animation & $0.0337(0.2329)$ \\
\hline \multicolumn{4}{|c|}{ Rate of Decline } \\
\hline User Rating & $-0.0081(0.0072)$ & Director Appeal & $-0.0615(0.0147)^{* * *}$ \\
\hline Critic Rating & $-0.0069(0.0005)^{* * *}$ & Star Appeal & $-0.0687(0.0126)^{* * *}$ \\
\hline
\end{tabular}

Table 7. Estimation Results for Heterogeneous Rate of Decay

The coefficients for the rate of decline parameters show that higher critic rating, star appeal, and director appeal all slow the rate of revenue decline. The coefficient for user rating is very close to zero, suggesting that this variable does not significantly influence the rate of decline. Also note that the estimated revenue loss is lower in this version of the model than in the previous version using a homogeneous rate of decline. This suggests it is important to account for heterogeneous rates of sales decline in our model.

We further investigate whether the quality of the pirated copy moderates the effect on box office revenue. To do this, we extend equation (4) as follows: 


$$
\ln \left(y_{i t}\right)=\mathbf{X}_{\mathbf{i}}^{\prime} \boldsymbol{\beta}_{\mathbf{i}}-\mathbf{Z}_{\mathbf{i}}^{\prime} \boldsymbol{\gamma}_{\mathbf{i}} t+\rho_{1} \text { Pir }_{i}+\rho_{2} \text { Pirqual }_{i}-\tau_{1} \text { Pir }_{i} t-\tau_{2} \text { Pirqual }_{i} t+\varepsilon_{i t}^{*}
$$

Where Pirqual $_{i}$ is the Pirated Quality variable described in Table 2. The result of the estimation is reported below in Table 8 . While the moderating effect of piracy quality on market potential and on the rate of sales decline are both negative as expected, they are both statistically insignificant. This suggests that the measures of quality available in our dataset have no statistically significant moderating effect on the impact of prerelease piracy on sales.

\begin{tabular}{l|l}
\hline \hline Parameter & Estimate \\
\hline$\tau_{1}$ & $-0.0963(0.0208)^{* * *}$ \\
$\tau_{2}$ & $-0.0162(0.0126)$ \\
$\rho_{1}$ & $-0.4022(0.1746)^{*}$ \\
$\rho_{2}$ & $-0.0669(0.1066)$ \\
\hline \hline
\end{tabular}

Table 8. Impact of Piracy Quality

In summary, these estimates show that pre-release piracy leads to a reduction in theatrical revenue, and that the impact is more pronounced in the earlier weeks after a movie's theatrical release. The net effect of pre-release piracy is an almost $20 \%$ revenue loss compared with piracy that only occurs post-release. As such, our estimated $20 \%$ revenue loss should not be interpreted as the total impact of piracy on movie revenue, but rather is only the additional impact from pre-release piracy compared with the more typical case of piracy that occurs at or after release.

\section{Alternative Analyses and Robustness Checks}

In this section, we discuss several alternative models and robustness checks on our main results. These analyses help ensure the reliability and robustness of the results, and shed light on additional factors that may influence our results. We discuss four analyses in this section: propensity-score matching of pre- and post-release pirated movies, incorporating timing of piracy relative to release, an alternative estimation without imputation of production budget, and robustness checks on the number of weeks used. 


\subsection{Propensity-Score Matching}

Because pre-release piracy pre-dates the official release of the movie, and therefore box office revenue, simultaneity is not a major concern in evaluating the causal impact of our analysis. However, other potential sources of endogeneity may still exist. While we have made efforts to control for as many other variables as our data allow, in this section we further address potential endogeneity concerns by performing a pair-wise propensity score matching analysis, and repeating our test on the matched dataset.

Our exploratory data analysis shows that while pre-release pirated movies are generally similar to other movies, certain types of movies are still overrepresented in the pre-pirated set. As such, it is prudent to perform propensity score matching to ensure the robustness of results. Propensity score matching in this way will address possible selection bias by ensuring that pirated movies are compared with movies that are similarly likely to be pirated, but were not. ${ }^{20}$ In our analysis, we calculate the propensity scores of a movie being pirated prior to release by using a binary-logit model to regress the piracy indicator variable over all observed movie characteristics. Each pirated movies is then paired with a movie with a similar pre-release piracy propensity score, but which was not pirated prior to the theatrical release. We then repeat the estimation we conducted in section 4.2 to evaluate the effect of piracy on these matched titles.

We report our estimates using these paired samples in Table 9. Compared with the estimates reported in Table 7 , we can see that fewer parameters are statistically significant in this estimation. This is because the propensity score matching technique results in fewer movies used for estimation. However, most results remain qualitatively the same, including the effect of budget, screen, director and user ratings, and genre, rating, and distributor effects. More importantly, the estimates of pre-release piracy's effect on market potential and rate of decline, -0.4874 and -0.1204 respectively, are both close to the corresponding estimates reported in Table 7 (-0.4024 and -0.0965). This confirms that our estimated effects of pre-release piracy are robust to selection effects.

\footnotetext{
20 Propensity score matching works well for large datasets, while our dataset contains a limited number of pirated movies. Therefore, in our study it is more appropriate to use propensity score matching as a robustness check, as opposed to as the main method of analysis.
} 


\begin{tabular}{|c|c|c|c|}
\hline Parameter & Estimate & Parameter & Estimate \\
\hline Constant & $7.9259(3.1922)^{*}$ & Warner & $-0.5336(0.3554)$ \\
\hline$\tau$ & $-0.1204(0.0280)^{* * *}$ & Universal & $0.5473(0.3542)$ \\
\hline$\rho$ & $-0.4874(0.2228)^{*}$ & Paramount & $-0.1750(0.3372)$ \\
\hline$\lambda$ & $0.8232(0.0264)^{* * *}$ & Fox & $0.9990(0.4215)^{*}$ \\
\hline Budget & $0.3814(0.1887)^{*}$ & Sony & $0.4926(0.4726)$ \\
\hline MissingBudget & $-1.8128(0.2972)^{* * *}$ & Newline & $1.1203(0.5770)$. \\
\hline Screen & $0.3458(0.1343)^{*}$ & Lionsgate & $0.1972(0.7626)$ \\
\hline Director Appeal & $0.4061(0.3160)$ & MGM & -0.8595 (0.4384). \\
\hline User Rating & $0.2665(0.2456)$ & Action & $0.5540(0.3265)$ \\
\hline Critic Rating & $-0.0046(0.0114)$ & Comedy & $0.5199(0.3615)$ \\
\hline Star Appeal & $-0.0560(0.2471)$ & Drama & $0.2920(0.3309)$ \\
\hline G & $-0.4504(0.8218)$ & Adventure & $0.4485(0.3964)$ \\
\hline $\mathrm{R}$ & $-0.9812(0.3496)^{* *}$ & Horror & $1.5606(0.5226)^{* *}$ \\
\hline \multirow[t]{2}{*}{ PG13 } & $0.0447(0.3204)$ & Thriller & $0.6404(0.5393)$ \\
\hline & & Animation & $0.5896(0.9008)$ \\
\hline \multicolumn{4}{|c|}{ Rate of Decline } \\
\hline User Rating & $-0.0496(0.0290)$ & Director Appeal & $-0.0368(0.0346)$ \\
\hline Critic Rating & $-0.0077(0.0014)^{* * *}$ & Star Appeal & $-0.0730(0.0294) *$ \\
\hline
\end{tabular}

AIC: 1340, BIC: 1496

Standard errors are given in parenthesis. The significance of the estimates are denoted by the following codes: $<0.001$ : $^{*} * *$ ',$<0.01$ : $^{\text {'**) }},<0.05$ : '*' $<0.1$ : '?

Table 9. Estimation Results for Propensity Score Matching

\subsection{The Timing of Piracy on Box Office Revenue}

As Figure 1 illustrates, although clustered around a movie's theatrical release, there is significant variation in the timing of pre-release piracy. A natural question to ask is whether the timing of the pre-release pirated version moderates its effects on box office revenue. To investigate this, we extend equation (4) as follows:

$$
\ln \left(y_{i t}\right)=\mathbf{X}_{\mathbf{i}}^{\prime} \boldsymbol{\beta}_{\mathbf{i}}-\mathbf{Z}^{\prime}{ }_{\mathbf{i}} \boldsymbol{\gamma}_{\mathbf{i}} t+\rho_{1} \text { Pir }_{i}+\rho_{2} \ln \left(\text { Pirweek }_{i}\right)-\tau_{1} \text { Pir }_{i} t-\tau_{2} \ln \left(\text { Pirweek }_{i}\right) t+\varepsilon_{i t}^{*}
$$

In equation (7), Pirwee $_{i}$ is the number of weeks before release that a pirated version became available (ln(Pirweek) is set to zero if no pre-release piracy occurs). The estimation result for this model is reported in Table 10. 


\begin{tabular}{l|ll|c}
\hline \hline Parameter & Estimate & Parameter & Estimate \\
\hline Constant & $7.5555(1.2449)^{* * *}$ & Warner & $0.2324(0.1617)$ \\
$\tau_{1}$ & $-0.0964(0.0208)^{* * *}$ & Universal & $0.4713(0.1838)^{*}$ \\
$\rho_{1}$ & $-0.3992(0.1745)^{*}$ & Paramount & $0.2893(0.1763)$ \\
$\rho_{2}$ & $-0.1999(0.1696)$ & Fox & $0.1779(0.1560)$ \\
$\lambda$ & $0.7503(0.0064)^{* * *}$ & Sony & $0.4536(0.1630)^{* *}$ \\
Budget & $0.3826(0.0760)^{* * *}$ & Newline & $-0.0428(0.2166)$ \\
MissingBudget & $-0.8917(0.1255)^{* * *}$ & Lionsgate & $0.5001(0.2189)^{*}$ \\
Screen & $0.4200(0.0783)^{* * *}$ & MGM & $-0.5458(0.2119)^{*}$ \\
Director Appeal & $0.0311(0.1304)$ & Action & $-0.0016(0.1587)$ \\
User Rating & $0.1420(0.0649)^{*}$ & Comedy & $0.4380(0.1430)^{* *}$ \\
Critic Rating & $-0.0045(0.0045)$ & Drama & $-0.1596(0.1487)$ \\
Star Appeal & $-0.1379(0.1105)$ & Adventure & $0.3676(0.2188)$. \\
G & $0.6083(0.2641)^{*}$ & Horror & $0.4324(0.1798)^{*}$ \\
R & $-0.7945(0.1616)^{* * *}$ & Thriller & $0.1066(0.1629)$ \\
PG13 & $-0.2014(0.1403)$ & Animation & $0.0267(0.2326)$ \\
\hline \multicolumn{2}{|c}{ Rate of Decline } \\
User Rating & $-0.0082(0.0072)$ & Director Appeal & $-0.0613(0.0147)^{* * *}$ \\
Critic Rating & $-0.0069(0.0005)^{* * *}$ & Star Appeal & $-0.0685(0.0126)^{* * *}$ \\
$\tau_{2}$ & $-0.0058(0.0203)$ & & \\
\hline \hline
\end{tabular}

AIC: 6280, BIC: 6506

Standard errors are given in parenthesis. The significance of the estimates are denoted by

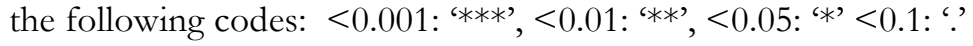

Table 10. Estimation Results for Timing of Pre-release Piracy

The results are very close to those reported in Table 7. Specifically, pre-release piracy both reduces the expected revenue $\left(\rho_{1}=-0.3992\right)$ and flattens the revenue curve $\left(\tau_{1}=-0.0964\right)$. In addition to this average effect, however, this is no conclusive evidence on the effect of the timing of pre-release piracy: while the coefficient of Pirweek $k_{i}$ for market potential is -0.1999 , suggesting that earlier pre-release piracy reduces expected revenue, this result is not statistically significant. Furthermore, the coefficient of Pirweek $k_{i}$ for the rate of decline is -0.0058 , very close to zero and statistically insignificant. 


\begin{tabular}{|c|c|c|c|c|c|}
\hline \multirow{2}{*}{\multicolumn{2}{|c|}{ Variable }} & \multicolumn{2}{|c|}{ With Pre-release Piracy } & \multicolumn{2}{|c|}{ Without Pre-release Piracy } \\
\hline & & Mean & $\begin{array}{l}\text { Standard } \\
\text { Deviation }\end{array}$ & Mean & $\begin{array}{l}\text { Standard } \\
\text { Deviation }\end{array}$ \\
\hline \multicolumn{2}{|c|}{ Box Office ( $\$$ million) } & 59.88 & 66.50 & 65.84 & 70.91 \\
\hline \multicolumn{2}{|c|}{ Budget ( $\$$ million) } & 48.43 & 45.74 & 49.80 & 47.81 \\
\hline \multicolumn{2}{|c|}{ Opening Screens } & 1910 & 1090 & 2590 & 927 \\
\hline \multicolumn{2}{|c|}{ Director Appeal } & 0.25 & 0.44 & 0.25 & 0.43 \\
\hline \multicolumn{2}{|c|}{ Star Appeal } & 0.58 & 0.50 & 0.47 & 0.50 \\
\hline \multicolumn{2}{|l|}{ User Rating } & 7.16 & 0.89 & 6.18 & 1.23 \\
\hline \multicolumn{2}{|l|}{ Critic Rating } & 50.03 & 18.83 & 40.04 & 16.86 \\
\hline \multirow[t]{8}{*}{ Distributor } & Warner & 0.13 & 0.33 & 0.14 & 0.34 \\
\hline & Universal & 0.15 & 0.36 & 0.09 & 0.29 \\
\hline & Paramount & 0.15 & 0.36 & 0.12 & 0.32 \\
\hline & Fox & 0.10 & 0.30 & 0.16 & 0.37 \\
\hline & Sony & 0.08 & 0.27 & 0.15 & 0.36 \\
\hline & Newline & 0.03 & 0.16 & 0.05 & 0.23 \\
\hline & Lionsgate & 0.05 & 0.22 & 0.06 & 0.24 \\
\hline & MGM & 0.05 & 0.22 & 0.06 & 0.24 \\
\hline \multirow[t]{3}{*}{ Rating } & G & 0.05 & 0.22 & 0.02 & 0.15 \\
\hline & $\mathrm{R}$ & 0.50 & 0.51 & 0.33 & 0.47 \\
\hline & PG13 & 0.30 & 0.46 & 0.46 & 0.5 \\
\hline \multirow[t]{7}{*}{ Genre } & Action & 0.13 & 0.33 & 0.13 & 0.34 \\
\hline & Comedy & 0.16 & 0.36 & 0.30 & 0.46 \\
\hline & Drama & 0.48 & 0.51 & 0.19 & 0.39 \\
\hline & Adventure & 0.10 & 0.30 & 0.08 & 0.27 \\
\hline & Horror & 0.03 & 0.16 & 0.13 & 0.33 \\
\hline & Thriller & 0.08 & 0.27 & 0.13 & 0.34 \\
\hline & Animation & 0.05 & 0.22 & 0.07 & 0.26 \\
\hline \multicolumn{2}{|c|}{ Pirated Quality } & 7.25 & 1.31 & 6.07 & 1.57 \\
\hline \multicolumn{2}{|c|}{ Pre-Release Piracy Indicator } & 1.00 & 0.00 & 0.00 & 0.00 \\
\hline \multicolumn{2}{|c|}{ Pre-Release Piracy Week } & 6.53 & 11.38 & $\mathrm{NA}$ & \\
\hline \multicolumn{2}{|c|}{ Number of Observations } & 40 & & 335 & \\
\hline
\end{tabular}

Table 11. Descriptive Statistics for Movies with and without Pre-release Piracy, but only for those movies whose production budget is known.

\subsection{Estimation without Imputation of Production Budgets}

As noted above, 117 movies in our data are missing production budget information. In our main analysis, we set the production budget of all these movies to the population average and use an indicator variable to capture the missing budget status. This is a standard imputation method, and it allows us to utilize 
more data for our analysis. However, one may argue that a smaller dataset without this imputation is less subject to model misspecification. Considering this, in this section we estimate the model using only movies with known production budgets. This smaller dataset consists of 375 movies, 40 of which have pre-release piracy (see Table 11 for descriptive statistics). The estimation results for this limited sample are reported in Table 12. Most estimates in Table 12 are fairly close to those reported in Table 7, further validating the robustness of the main results. ${ }^{21}$

\begin{tabular}{|c|c|c|c|}
\hline Parameter & Estimate & Parameter & Estimate \\
\hline Constant & $6.4507(1.2693)^{* * *}$ & Warner & $0.1473(0.1735)$ \\
\hline$\tau$ & $-0.1201(0.0218)^{* * *}$ & Universal & $0.4273(0.2048)^{*}$ \\
\hline$\rho$ & $-0.4874(0.1831)^{* *}$ & Paramount & $0.2920(0.1900)$ \\
\hline$\lambda$ & $0.7310(0.0069)^{* * *}$ & Fox & $0.2430(0.1710)$ \\
\hline \multirow[t]{2}{*}{ Budget } & $0.5121(0.0785)^{* * *}$ & Sony & $0.5252(0.1761)^{* *}$ \\
\hline & & Newline & $-0.0929(0.2407)$ \\
\hline Screen & $0.2534(0.0797)^{* *}$ & Lionsgate & $0.6541(0.2390)^{* *}$ \\
\hline Director Appeal & $0.0163(0.1362)$ & MGM & $-0.2830(0.2348)$ \\
\hline User Rating & $0.1815(0.0730)^{*}$ & Action & $0.0404(0.1624)$ \\
\hline Critic Rating & $-0.0062(0.0048)$ & Comedy & $0.5497(0.1562)^{* * *}$ \\
\hline Star Appeal & $-0.2158(0.1198)$. & Drama & $-0.0064(0.1601)$ \\
\hline G & 0.6799 (0.3491). & Adventure & $0.4493(0.2134)^{*}$ \\
\hline $\mathrm{R}$ & $-0.8144(0.1781)^{* * *}$ & Horror & $0.6000(0.1914)^{* *}$ \\
\hline \multirow[t]{2}{*}{ PG13 } & $-0.2377(0.1560)$ & Thriller & $0.1287(0.1732)$ \\
\hline & & Animation & $0.0628(0.2486)$ \\
\hline \multicolumn{4}{|c|}{ Rate of Decay } \\
\hline User Rating & $0.0004(0.0081)$ & Director Appeal & $-0.0592(0.0152)^{* * *}$ \\
\hline Critic Rating & $-0.0072(0.0005) * * *$ & Star Appeal & $-0.0494(0.0137)^{* * *}$ \\
\hline
\end{tabular}

AIC: 4777 , BIC: 4977

Standard errors are given in parenthesis. The significance of the estimates are denoted by

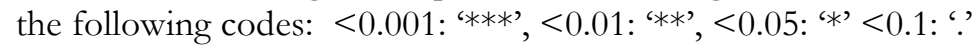

Table 12. Estimation Results Using only Movies with Known Product Budget

\subsection{Alternative Numbers of Weeks}

Our analysis above uses only movies that have been in theaters for at least six weeks. To ensure that the choice of this threshold is not driving the results, we repeated our analysis using different thresholds,

\footnotetext{
${ }^{21}$ The use of imputed values and removing records with missing values are both commonly used empirical approaches. Our result is robust to both specifications.
} 
ranging from 4 to 9 . The estimates of the effects of piracy on market potential and rate of decline are reported in Table 13. The estimates are similar across different threshold values, further validating the robustness of these results.

\begin{tabular}{l|cc}
\hline \hline Number of Weeks & $\boldsymbol{\tau}$ & $\boldsymbol{\rho}$ \\
\hline 4 & $-0.0716(0.0313)^{*}$ & $-0.3231(0.1555)^{*}$ \\
5 & $-0.1013(0.0249)^{* * *}$ & $-0.4048(0.1637)^{*}$ \\
6 & $-0.0965(0.0208)^{* * *}$ & $-0.4024(0.1746)^{*}$ \\
7 & $-0.0963(0.0177)^{* * *}$ & $-0.4212(0.1799)^{*}$ \\
8 & $-0.0841(0.0151)^{* * *}$ & $-0.4673(0.1814)^{*}$ \\
9 & $-0.0937(0.0140)^{* * *}$ & $-0.4654(0.1859)^{*}$ \\
\hline \hline
\end{tabular}

Table 13. Estimation Results using Alternative Week Thresholds

\section{Discussion}

Motion picture studios have limited resources to fight piracy, and must allocate these resources intelligently across different portions of a product's lifecycle. Many in the industry believe that piracy could be particularly harmful in the period prior to a movie's official release for two main reasons. First, there are no legal alternative channels where consumers can consume the movie. Second, because pre-release piracy presumably comes disproportionately from those individuals most passionate about and most interested in watching the movie. However, some argue that pre-release piracy will have no impact on movie revenue, or could even help theatrical revenue by increasing the buzz for the movie or by complementing the higher quality experience consumers get from viewing the movie in the theater. As such, the impact of pre-release piracy on movie box office revenue has important implications for managers in terms of allocating scarce resources for piracy protection. Likewise, the impact of pre-release piracy has important implications for policymakers in the context of balancing the benefits and costs of potential policy interventions.

Our research informs this managerial and policy question by being the first paper we are aware of to empirically analyze the impact of pre- release movie piracy on box office revenue. Using data collected from a unique Internet site which provides information about the timing and quality of pirate sources, and by combining this with information on box office revenue and various other movie characteristics, we find that pre-release piracy significantly reduces a movie's expected box office revenue and that this impact is stronger 
earlier in a movie's lifecycle than in later periods. When these effects are combined, we find that, on average, pre-release piracy reduces box office revenue by 19\% compared to an environment where piracy occurs after the theatrical release. Our results are robust to a variety of alternative model specifications and validations.

Our results contribute to the literature in several ways. First, they fill a gap in the literature by presenting evidence of the impact of Internet-based movie piracy on important managerial and policy questions regarding box office revenue. Second, by taking a pre-release perspective, we address several factors that complicate the analysis in most existing studies of piracy. Finally, pre-release piracy may be qualitatively different than other types of piracy: whereas in other types of piracy those with low willingness to pay may disproportionately use the pirated copies, in the case of pre-release piracy those who download the pirated copy are likely to be the most enthusiastic customers, potentially making the threat of revenue loss more severe.

We note that there are several limitations of the data used in this study. First, although we can infer the existence of pre-release piracy from our data, we do not have information on the intensity of pre-release downloads of the pirated copies. Having download intensity information could further strengthen the causal inference of the impact of piracy. Second, piracy may impact different types of movies to different extents. With a richer dataset and more sophisticated models, we could analyze these differential effects. Third, our information on piracy quality is limited to self-reported subjective evaluations of users of a single website. Having more robust "quality" information would allow us to better evaluate the differential impact of "high" and "low" quality piracy leaks on theatrical revenue. Fourth, in our data we only observe box-office revenue and not subsequent revenues from other important sources like DVD sales. These data limitations point to potential useful directions for future research on this important topic. 


\section{References}

Ainslie, Andrew, Xavier Dreze, and Fred Zufryden (2005), "Modeling Movie Life Cycles and Market Share", Marketing Science, 24 (3), 508-517.

Bai, J., J. Waldfogel (2012), "Movie Piracy and Sales Displacement in Two Samples of Chinese Consumers", Information Economics and Policy, 24(3) 187-196.

Bounie, David, Marc Bourreau and Patrick Waelbroeck (2006), "Piracy and the Demand for Films: Analysis of Piracy Behavior in French Universities", Review of Economic Research on Copyright Issues, 3 (2), 15-27.

Danaher, B., S. Dhanasobhon, M.D. Smith, R. Telang (2010), "Converting Pirates without Cannibalizing Purchasers: The Impact of Digital Distribution on Physical Sales and Internet Piracy", Marketing Science, 29(6) 1138-1151.

Danaher, Brett, Michael D. Smith (2014), "Gone in 60 Seconds: The Impact of the Megaupload Shutdown on Movie Sales", International Journal of Industrial Organization. 33 1-8.

Danaher, Brett, Michael D. Smith, Rahul Telang (2014), "Piracy and Copyright Enforcement Mechanisms", Lerner and Stern, eds. Innovation Policy and the Economy, Volume 14, University of Chicago Press, Chicago, Illinois.

Danaher, Brett and Joel Waldfogel (2012), "Reel Piracy: The Effect of Online Film Piracy on International Box office revenue", SSRN Working Paper.

Dellarocas, Chrysanthos, Xioaquan Zhang, and Naveen F. Awad (2007) "Exploring the Value of Online Product Reviews in Forecasting Sales: The Case of Motion Pictures", Journal of Interactive Marketing, 21, 4 (Autumn), 23-45.

De Vany, A.S., W.D. Walls. (2010), "Estimating the Effects of Movie Piracy on Box-office Revenue”, Review of Industrial Organization 30:291-301.

Duan, Wenjing, Bin Gu, and Andrew B. Whinston (2008), "Do online reviews matter? - An empirical investigation of panel data”, Decision Support Systems, 45, 4 (November), 1007-1016.

Elberse, Anita (2007), “The Power of Stars: Do Star Actors Drive the Success of Movies?”, Journal of Marketing, 71, 4 (October), 102-120.

Eliashberg, J., A. Elberse, M. A. A. M. Leenders (2006), "The motion picture industry: Critical issues in practice, current research, and new research directions", Marketing Science, 25(6) 638-661.

Eliashberg, Jehoshua, Samuel K. Hui, and Z. John Zhang (2007), "From Story Line to Box Office: A New Approach for Green-Lighting Movie Scripts”, Management Science, 53, 6 (June), 1097-1110.

Eliashberg, Jehoshua, Jedid-Jah Jonker, Mohanbir S. Sawhney, and Berend Wierenga (2000), "MOVIEMOD: An Implementable Decision Support System for Prerelease Market Evaluation of Motion Pictures", Marketing Science, 19 (3): 226-243. 
Eliashberg, Jehoshua and Steven M. Shugan (1997), "Film Critics: Influencers or Predictors?”, Journal of Marketing, 61, 2 (April), 68-78.

Hammond, R.G. Forthcoming, "Profit Leak? Pre-Release File Sharing and the Music Industry", Southern Economic Journal, forthcoming.

Hennig-Thurau, Victor Henning, and Henrik Sattler (2007), "Consumer File Sharing of Motion Pictures", Journal of Marketing, 71, 4 (October), 1-18.

Krider, Robert E. and Charles B. Weinberg (1998), "Competitive Dynamics and the Introduction of New Products: The Motion Picture Timing Game”, Journal of Marketing Research, 35, 1 (February), 1-15.

Lee, Jonathan, Peter Boatwright, and Wagner A. Kamakura (2003), “A Bayesian Model for Prelaunch Sales Forecasting of Recorded Music", Management Science, 49 (2): 179-196.

Lehmann, Donald R. and Charles B. Weinberg (2000), "Sales through Sequential Distribution Channels: An Application to Movies and Videos", Journal of Marketing, 64 (3), 18-33.

Rennhoff, A.D. and Wilbur, K.C. (2008), “The Effectiveness of Post-Release Movie Advertising”, Working Paper.

Rob, R. and Waldfogel J. (2007), "Piracy on the Silver Screen", Journal of Industrial Economics, 55, 3 (Sept), 379395.

Sawhney, M.S. and Eliashberg, Jehoshua (1996), “A Parsimonious Model for Forecasting Gross Box-Office Revenues of Motion Pictures”, Marketing Science, 15, 2, 113-131.

Smith, Michael D. and Rahul Telang (2009), "Competing with Free: The Impact of Movie Broadcasts on DVD Sales and Internet Piracy”, MIS Quarterly, 33, 2, 321-338.

Stelter, Brian (2009), "Piracy Puts Film Online One Month Before Open”, New York Times, April 1, 2009.

Swami, S., Jehoshua Eliashberg, Charles B. Weinberg (1999), "SilverScreener: A Modeling Approach to Movie Screens Management”, Marketing Science, 18, 3, 352-372.

Zentner, Alejandro (2010), "Measuring the Impact of File Sharing on the Movie Industry: An Empirical Analysis Using a Panel of Countries", SSRN Working Paper \#1792615. 